\title{
DOSSIER
}

\section{CAMPAÑAS DE VACUNACIÓN CONTRA LAS ENFERMEDADES VÍRICAS EN ESPAÑA DURANTE EL SIGLO XX: UNA VISIÓN DESDE LA PRENSA (1951-1986) ${ }^{1}$}

\author{
Noelia M. Martín Espinosa \\ Facultad de Fisioterapia y Enfermería de Toledo. UCLM. \\ Email: Noelia.Martin@uclm.es \\ ORCID iD: http://orcid.org/0000-0002-1298-6976
}

María Victoria Caballero Martínez

Profesora asociada. Facultad de Medicina de Ciudad Real. UCLM. Email: MVictoria.Caballero@uclm.es

ORCID iD: http://orcid.org/0000-0003-1883-5607

Lourdes Mariño Gutiérrez

Escuela Nacional de Sanidad. Instituto de Salud Carlos III. Madrid

Email: Imarino@isciii.es

ORCID iD: http://orcid.org/0000-0001-8569-7502

Recibido: 24 febrero 2018; Aceptado: 20 octubre 2019

Cómo citar este artículo/Citation: Martín Espinosa, Noelia M.; Caballero Martínez, María Victoria; Mariño Gutiérrez, Lourdes (2020), “Campañas de vacunación contra las enfermedades víricas en España durante el siglo XX: una visión desde la prensa (1951-1986)", Asclepio 72 (1):p296. https://doi.org/10.3989/asclepio.2020.05.

RESUMEN: Desde finales del siglo XIX, fue posible luchar contra varias de las enfermedades víricas (rabia, viruela, gripe, polio, sarampión, rubéola y parotiditis), que, a lo largo del siglo XX, afectaron masivamente a la población adulta e infantil, a través de programas de vacunación que se establecieron una vez que estuvieron disponibles vacunas seguras para prevenirlas. España fue adoptando estas medidas preventivas progresivamente, especialmente a partir de su incorporación a la Organización Mundial de la Salud (OMS) en 1951. Cuando se promulgó la Ley General de Sanidad, en 1986, algunas de estas enfermedades habían podido controlarse y/o eliminarse mediante la vacunación sistemática. El tratamiento que ha realizado la prensa nacional de estos hechos ha sido escasamente estudiado. Este artículo tiene como objetivo analizar la repercusión en la prensa nacional de las campañas de vacunación contra estas enfermedades víricas hasta el año 1986 y comprobar si los medios de comunicación escritos reflejaron las medidas epidemiológicas globales adoptadas por la OMS para combatirlas. Junto a ello, estudiar su posible influencia, tanto en la puesta en marcha de políticas públicas de vacunación, como en el modo de transmitir dicha información a la población en los diferentes contextos sociopolíticos y científico-sanitarios cambiantes del periodo estudiado.

PALABRAS CLAVE: Vacunación; Organización Mundial de la salud; prensa escrita; España; Epidemiología.

\section{VACCINATION CAMPAIGNS AGAINST VIRAL DISEASES IN SPAIN DURING THE 20TH CENTURY: A VIEW} FROM THE PRESS (1951-1986)

ABSTRACT: Since the end of the 19th century, it has been possible to fight against several viral diseases (smallpox, rabies, influenza, polio, measles, rubella and mumps) that, during the 20th century, had a massive effect on the adult and child population through vaccination programmes established when safe vaccines were available to prevent such diseases. Spain progressively incorporated these preventive measures, especially after its incorporation into the World Health Organization (WHO) in 1951. By the time the General Health Law was enacted in 1986, it had been possible to control and/or eliminate some of these diseases through systematic vaccination.

The treatment and monitoring that the Spanish national press has given to the implementation of the vaccination campaigns against these diseases has been little studied. Therefore, the objectives of this paper are to analyse the repercussions in the national press of the vaccination campaigns against these viral diseases between 1951 and 1986 and to check whether the written media reflected the global epidemiological measures adopted by WHO to combat them. Besides, to study its possible influence both in the development of public policies of vaccination and in the way how this information was transmitted to the population during the different socio-political and scientific contexts in the studied period.

KEY WORDS: Vaccination; World Health Organization; Written media; Spain; Epidemiology.

Copyright: ( 2020 CSIC. Este es un artículo de acceso abierto distribuido bajo los términos de la licencia de uso y distribución Creative Commons Reconocimiento 4.0 Internacional (CC BY 4.0). 


\section{INTRODUCCIÓN}

Desde finales del siglo XIX, cuando se desarrolló la vacuna antirrábica, ha sido posible prevenir varias enfermedades víricas (viruela, rabia, gripe, polio, sarampión, rubéola y parotiditis) que afectaban masivamente a la población adulta e infantil. La historiografía global sobre inmunizaciones ha marcado una serie de etapas en su desarrollo (Moulin, 1996), que nos permiten enmarcar estudios particulares sobre una u otra vacuna o un conjunto de ellas, como ocurre con las que vamos a estudiar. A lo largo del siglo $\mathrm{XX}$, a medida que se iba contando con vacunas seguras para prevenirlas, se fueron estableciendo programas de vacunación. España fue incorporando estas medidas preventivas, especialmente a partir de su incorporación a la OMS, en 1951, lo que supuso la aceptación por parte del país de las directrices de salud pública marcadas por esta institución internacional, materializadas posteriormente con la puesta en marcha de varios programa-país (Ballester Añón, 2016). En la década de los 50, la elevada incidencia y letalidad alcanzada por algunas enfermedades transmisibles víricas, como la gripe y la poliomielitis, las convirtieron en uno de los problemas de salud pública más importantes a nivel mundial. Por ello, uno de los ejes de acción de la OMS fue la lucha contra estas enfermedades en el contexto internacional.

En España, la asunción de estas nuevas directrices supuso un cambio en la política sanitaria del franquismo, que tuvo que adaptar y modernizar su precaria situación estructural para dar respuesta a estos nuevos requerimientos (Marset Campos, et al, 1995). José Alberto Palanca y Jesús García Orcoyen fueron los responsables sucesivos de la Dirección General de Sanidad, el primero de ellos en la etapa inicial de incorporación de España al organismo internacional, el segundo desde 1957 a 1973, etapa en la que las políticas sanitarias y de salud pública estuvieron muy influenciadas por la lucha de poder entre las distintas familias franquistas (Molero Mesa, 1994).

Un hito fundamental fue la implantación del primer calendario oficial de vacunación infantil en 1975, que incluyó la poliomielitis y el sarampión. Cuando se promulgó la Ley General de Sanidad, en 1986, algunas de las enfermedades víricas habían podido ser controladas y/o eliminadas mediante la implantación de campañas o programas de vacunación sistemática.
El doble papel de la prensa de información general, como suministradora de información y como creadora de opinión, ha sido clave en la materialización práctica de los programas de inmunización establecidos, con igual, mayor o menor peso de ambas facetas, dependiendo de los contextos particulares.

El tratamiento y seguimiento que la prensa española de carácter nacional ha realizado de la inmunización contra las enfermedades anteriormente citadas ha sido escasamente estudiado en su conjunto, aunque recientemente contamos con una serie de estudios valiosos que suponen aportaciones relevantes y que reflejan el interés que despierta el uso de la prensa general en la historiografía de las vacunas en España (Duro Torrijos, 2014; Duro Torrijos, Tuells Hernández, 2015; Martínez Martínez, 2016). El trabajo de Martínez aborda un periodo que, en parte, se solapa con el nuestro, e incluye las noticias publicadas en la prensa española sobre inmunizaciones en enfermedades como la poliomielitis, meningitis, viruela y el virus del papiloma humano.

El presente trabajo pretende analizar la repercusión en la prensa nacional de las campañas de vacunación contra estas enfermedades víricas entre 1951 y 1986 y comprobar hasta qué punto los medios de comunicación escritos reflejaron las recomendaciones establecidas por la OMS para combatirlas. Junto a ello, estudiar su posible influencia, tanto en la puesta en marcha de políticas públicas de inmunización, como en el modo de transmitir dicha información a la población en los diferentes contextos sociopolíticos y científico-sanitarios cambiantes del periodo estudiado.

\section{MATERIAL Y MÉTODO}

Se han utilizado las noticias relacionadas con la vacunación contra las enfermedades infecciosas estudiadas, publicadas en tres diarios de tirada nacional: $A B C$ (y la revista ilustrada semanal Blanco y Negro, vinculada a este diario), La Vanguardia y Ya. Estas fuentes, aunque tuvieron en común la censura a la que fueron sometidas por el régimen franquista, pertenecían a diferentes núcleos de poder informativo e ideológico, razón por la cual constituyen una muestra representativa de la información general publicada en torno al tema de estudio.

Los diarios $A B C$, y La Vanguardia ofrecen acceso gratuito a sus hemerotecas electrónicas, mientras que 
ha sido necesaria una revisión manual de los ejemplares del diario Ya.

La delimitación del período de estudio a los años comprendidos entre 1951 y 1986 responde a los siguientes criterios. En el año 1951 España se incorpora a la OMS, en una primera etapa de apertura internacional que termina con el período autárquico de los primeros años del franquismo, lo que supuso la adopción de ciertas recomendaciones de salud pública promovidas por este organismo internacional. Por otro lado, en 1986, ya en época democrática, bajo el gobierno socialista de Felipe González, se publicó la Ley General de Sanidad, que supuso un cambio significativo en el modelo de atención sanitaria, incorporando los programas de inmunización. Por tanto, el estudio de este periodo resulta fundamental para ver la evolución de la política sanitaria franquista en materia preventiva desde su incorporación a la OMS, pasando por el período de la Transición, hasta llegar a su consolidación democrática, tras la publicación de la Constitución Española en 1978 (Rodríguez Ocaña, Martínez Navarro, 2008; Perdiguero, 2015).

Para la búsqueda en la hemeroteca digital del diario $\mathrm{ABC}$, se han utilizado los siguientes términos: viruela, rabia, gripe, polio, parotiditis, rubeola, rabia, combinados cada uno de ellos con el operador booleano " $Y$ " al término vacunación en el periodo de tiempo objeto de estudio (1951-1986).

Se han analizado todas las noticias publicadas excluyendo aquellas que sólo se referían tangencialmente al tema de estudio o trataban sobre vacunación en animales. De este modo se han obtenido los siguientes resultados:

- "Viruela y vacunación": 185 noticias, seleccionándose 101 . El periodo más prolífico en noticias fue el decenio 1965-1975, con 87 resultados, seleccionándose 36 .

- "Rabia y vacunación": 165 noticias, en su mayor parte (149) publicadas a partir de 1960, seleccionándose 52 .

- “Gripe y vacunación": 158 noticias, seleccionándose 47.

- "Polio y vacunación": 152 noticias, seleccionándose 48.

- "Parotiditis y vacunación": aparecen noticias únicamente a partir de 1968. Se obtuvieron 24 resultados, seleccionándose 11 .

- "Rubeola y vacunación": se encontraron resultados desde 1961, aunque la mayor parte de las noticias (49) se publicaron a partir de 1976. En total, se obtuvieron 61 resultados, seleccionándose 23.

- "Sarampión y vacunación": aparecen 83 noticias publicadas desde 1955, seleccionándose 45 .

La Hemeroteca digital del diario La Vanguardia no permite la búsqueda utilizando operadores booleanos, por lo que se buscó por la palabra clave "vacunación", utilizando como límite el período de estudio. Se obtienen 1.429 resultados de los que 150 están relacionados con el tema de estudio.

El diario "YA" se conserva en formato impreso en la Hemeroteca Municipal de Madrid, por lo que no ha sido posible la revisión de la totalidad de los ejemplares publicados en nuestro período de estudio, dado el amplio volumen de la colección. Por esa razón, se ha llevado a cabo una revisión de algunos años completos y meses, seleccionados por fechas relacionadas a algún suceso o hecho de interés para nuestra investigación, según informaciones previas². 178 noticias se relacionaron con el tema de estudio.

\section{CAMPAÑAS DE VACUNACIÓN CONTRA LA VIRUELA}

En España, la vacunación antivariólica se inició en los albores del siglo XIX (Santamaría, 1990), pero la precaria estructura sanitaria y la carencia de un marco legislativo e institucional dio paso a una etapa de regresión que dificultó su difusión, por lo que las epidemias de viruela siguieron produciéndose (Campos Marín, 2004). En 1860 la viruela fue incluida entre las enfermedades de Declaración Obligatoria y en 1871, una Real Orden creó el Instituto Nacional de la Vacuna ${ }^{3}$. En 1903 se implantó la vacunación obligatoria, desapareciendo la enfermedad en 1929, para reemerger posteriormente (Navarro García, 2002).

La Ley de 25 de noviembre de 1944 de Bases de Sanidad Nacional confirmó la obligatoriedad de la vacunación ${ }^{4}$, permitiendo que la viruela dejara de ser endémica a partir de 1948.

En los años 50, la mayor parte de las noticias relacionadas con las campañas de vacunación contra esta enfermedad, se refieren a lugares y horarios para la vacunación, haciendo de la prensa un medio de promoción de esta práctica preventiva. Como ejemplo "La vacunación antivariólica en Madrid. Los servicios 
sanitarios del Ayuntamiento están en condiciones de vacunar a toda la población de Madrid contra la viruela, para lo que cuenta con la dosis de vacuna suficiente..." a la vez que se destacaba que "...aunque si es recomendable (la vacunación), por la constante afluencia de personas que llegan de lugares donde es endémico el mal", haciéndose eco la prensa, del brote producido en la Bretaña francesa que ponía en riesgo a los no vacunados y que obligó a establecer controles internacionales a todos los viajeros y buques procedentes de Francia ${ }^{5}$. De hecho, el Director General de Sanidad, Dr. Palanca, compareció ante los medios de comunicación para informar sobre la "ausencia total" de casos en España, la disponibilidad de "equipos de médicos, practicantes y enfermeras para llevar a cabo una rápida y eficaz intervención" y la conveniencia de la inmunización periódica. Palanca concluía afirmando que "el estado sanitario del país no puede ser más satisfactorio ${ }^{6}$. No obstante, la alarma y la desconfianza de la población se prolongó durante meses, pues en el mes de abril se seguía desmintiendo en la prensa la aparición de casos de viruela, esta vez en Barcelona ${ }^{7}$.

En 1958, la OMS aprobó un Plan para conseguir la erradicación de la viruela en el mundo, estableciendo la pauta para la producción, conservación y distribución de su vacuna, así como las pruebas para comprobar su efectividad, aspectos que quedaron recogidos en un informe técnico del Grupo de Estudio de la OMS de $1959^{8}$.

España sufrió el último brote epidémico de viruela, ocurrido en Madrid, entre el 14 de febrero y el 5 de marzo de 1961, a partir de dos casos importados de la India, que ocasionaron veinte casos de viruela (Mariño y Báguena, 2016). Esta noticia se recogió en los diarios nacionales, tratando de minimizar la alarma, a la vez que destacaban la participación ciudadana en la campaña de vacunación gratuita decretada ante el brote 9 . Una visita a Barcelona de García Orcoyen sirvió para que afirmara que su origen era un "hecho accidental... facilitado... por los rápidos transportes actuales", destacando la correcta actuación sanitaria, ya que los casos se habían "aislado totalmente en el Hospital del Rey y realizado todas las técnicas más completas de determinación de contactos $y$ aislamiento"10. Posiblemente, este incidente generó bastante alarma social, apareciendo diversas noticias que insistían en la correcta actuación sanitaria adoptada, tanto con los enfermos, como con las medidas preventivas establecidas, concluyendo que las condi- ciones sanitarias de España eran excelentes, y justificando, así, la política sanitaria del régimen ${ }^{11}$. En 1962, España declaró a la OMS haber erradicado, por fin, la viruela. No obstante, debido a una financiación insuficiente para la producción local de la vacuna, se requirió de la ayuda económica del Comité de la Región Europea de la OMS (programa España 25). La necesidad de producir cantidad suficiente de vacuna también estuvo influida por la aparición de algunos brotes en otros países de Europa, como Suiza, Alemania y Gran Bretaña y por la obligación de vacunar contra la viruela a todos los viajeros procedentes de dichos países ${ }^{12}$.

En 1964 se publicó el Primer informe del Comité de Expertos de la OMS en viruela ${ }^{13}$ y la lucha internacional contra la enfermedad también se reflejó en la prensa española. A partir de 1965, aparecieron varias noticias que trataban sobre la erradicación de la viruela a nivel mundial, destacando el liderazgo de la OMS, que usó esta enfermedad como lema del Día Mundial de la Salud en diversas ocasiones: en 1965, "La viruela, amenaza constante"14, en 1975, "Viruela, imposible retroceder"15. Asimismo, la prensa mostraba estadísticas sobre la incidencia de la enfermedad en Europa y España, ya que, aunque ésta era muy baja, se insistía en la necesidad de controlar la enfermedad en todos los lugares del mundo.

En 1972, el director de la sección de Medicina de La Vanguardia celebraba el éxito en la lucha contra la enfermedad en el mundo gracias a la lucha liderada por la $\mathrm{OMS}^{16}$, al igual que destacaba en diversos artículos la importancia de mantener la guardia sobre la enfermedad hasta su completa erradicación ${ }^{17}$. A partir de 1975, hallamos noticias anunciando la inminente erradicación global de la enfermedad ${ }^{18}$. En el Día Mundial de la Salud de 1976, la OMS recordaba que la erradicación de la viruela estaba muy próxima, aunque enfatizaba sobre la lucha contra otras enfermedades infecciosas aún presentes: poliomielitis, rubeola, parotiditis, sarampión, meningitis, e insistía en la necesidad de realizar campañas de vacunación eficaces, contando con medios económicos suficientes para promoverlas, facilitando la participación de la población, ya que, en ocasiones, la ignorancia o el temor a la inmunización suponían rechazar vacunaciones consideradas de alta eficacia ${ }^{19}$. A partir de 1977, diversos diarios publicaron la no declaración de nuevos casos de viruela en el mundo, aunque la OMS estableció un periodo de dos años para proclamar su erradicación oficial ${ }^{20}$. 
Aunque su erradicación mundial se declaró oficialmente en diciembre de 1979, por parte de un Comité científico independiente, y fue ratificada en la $33^{a}$ Asamblea Mundial de la Salud de la OMS del 8 de mayo de $1980^{21}$, España mantuvo la obligatoriedad de la vacunación antivariólica hasta 1982.

\section{CAMPAÑAS DE VACUNACIÓN CONTRA LA RABIA}

La Declaración Obligatoria de la rabia en España se estableció en 1863. El Instituto Nacional de Higiene contó desde su fundación en 1899, con un Servicio de Rabia en el que se comenzó a elaborar la vacuna (Báguena y Mariño, 2017). En 1952, la Ley de 20 de diciembre sobre Epizootias hizo obligatoria la declaración de las enfermedades de los animales que constituían zoonosis peligrosas para la población humana, estableciendo su registro, matrícula y la vacunación antirrábica de los perros en los Ayuntamientos, y creando las Juntas provinciales para luchar contra la rabia, aspectos desarrollados posteriormente en el Decreto de 4 de febrero de $1955^{22}$. La Primera Asamblea Mundial de la Salud de la OMS ya consideró la lucha contra la rabia como una prioridad en materia de Salud Pública. El programa inicial de la OMS de asistencia y colaboración científico-técnica con España estableció un plan específico para la rabia, denominado España 1.3., que dio comienzo en 1952 (Báguena y Mariño, 2017).

La segunda sesión del Comité de Expertos sobre la Rabia, celebrada en 1953, informó sobre el estudio realizado para lograr un suero hiperinmune estándar internacional ${ }^{23}$. En 1956, este comité estableció las técnicas de laboratorio que debían aplicarse a partir de entonces en su tercer informe técnico, publicado en $1957^{24}$. La erradicación de la rabia en España se consiguió en 1959, tras la puesta en marcha de los programas de vacunación sistemática de los perros, aunque posteriormente se registraron algunos casos aislados de rabia animal (Navarro García, 2002).

Durante el periodo de estudio, la prensa, esporádicamente, publicaba alguna noticia sobre la rabia, destacando la necesidad de vacunar a los perros, los plazos y lugares de vacunación, o bien realizando llamamientos por algún caso de agresiones a humanos con resultados fatales, que requerían capturar al animal y vacunar a los contactos ${ }^{25}$. Así, se hizo eco de un caso de rabia humana en un niño de 9 años que falleció por la enfermedad en 1953 y de otro regis- trado en Málaga en el año $1975^{26}$. En ocasiones, se destacaba el éxito de las campañas antirrábicas desplegadas en diferentes localidades ${ }^{27}$, aunque también hubo alguna publicación referida a la carencia de vacuna, al corto plazo dedicado a las campañas o a las dificultades para participar en ellas ${ }^{28}$. Se publicó también algún artículo divulgativo ${ }^{29}$ que destacaba la importante labor de colaboración entre profesionales médicos y veterinarios en la "lucha integral" contra la enfermedad ${ }^{30}$ y de la necesaria coordinación entre países. Diversas noticias recogieron información referida a brotes de esta enfermedad en algunos países europeos ${ }^{31}$, resaltándose la ausencia de casos en España, como modo de ensalzar la efectividad de las medidas preventivas llevadas a cabo ${ }^{32}$. En 1973, el diario $A B C$ se hizo eco del anuncio por parte de la OMS de una nueva vacuna más eficaz, que simplificaba la inmunización contra la enfermedad ${ }^{33}$. A partir de 1976, se publicaron algunas noticias sobre la persistencia de una epidemia de rabia selvática en diversos países del norte de Europa, que avanzaba hacia el sur, según se refería," a una velocidad de $40 \mathrm{~km}$ por año y a más velocidad aún en las zonas boscosas" y que podría alcanzar España, obligando a las autoridades a desplegar un plan de vigilancia especial en la zona pirenaica a través de un mayor control sobre las importaciones de animales de compañía procedentes de los países infectados ${ }^{34}$. La preocupación por esta circunstancia llevó a la promulgación de una Orden del Ministerio de Gobernación, estableciendo medidas especiales para el control de los animales domésticos, especialmente de los animales vagabundos en las ciudades ${ }^{35}$.

A pesar de esta evolución favorable, en 1985, tras casi 20 años sin casos de enfermedad, se recogió la noticia de un brote de rabia canina que afectó a tres animales en Melilla, lo que obligó a reforzar las campañas de vacunación antirrábica, y llevó a prohibir la entrada o salida de perros y gatos de la ciudad ${ }^{36}$. La prensa solía destacar que se trataba de casos impor$\operatorname{tados}^{37}$, pero lo cierto es que la zoonosis había presentado cierta incidencia ocasional a lo largo del periodo.

\section{CAMPAÑAS DE VACUNACIÓN CONTRA LA GRIPE}

Los principales esfuerzos para el desarrollo de una vacuna contra la gripe se realizaron tras la pandemia de 1918, aunque la prevención de esta enfermedad mediante una vacuna ha sido problemática, debido 
a la importante capacidad de cambio antigénico de las cepas virales (Théodorides, 1991).

La OMS, desde su creación, tuvo en cuenta el grave problema de salud pública que representaba la gripe y, ya en 1947, reconoció la necesidad de la colaboración internacional en la lucha contra la enfermedad, planteando su primer Programa Mundial para la Gripe. En 1948 creó el primer Centro de Investigación de la Gripe (WIC) en Londres, con la función de recoger y difundir toda la información disponible sobre la enfermedad, además de coordinar y formar al personal de laboratorio para el estudio del virus, en colaboración con varios laboratorios regionales distribuidos por todo el mundo (Payne, 1953). En 1951, la OMS nombró un primer Comité de Expertos en Gripe, cuya primera sesión tuvo lugar en septiembre de $1952^{38}$.

La gripe fue una enfermedad de Declaración Obligatoria en nuestro país desde 1904 y hubo diversas experiencias en relación con su profilaxis (Porras GaIlo, 2008).

Las noticias publicadas sobre esta enfermedad fueron muy numerosas durante la pandemia de gripe asiática de 1957, apareciendo varios artículos escritos por médicos o especialistas en virología, en los que se describía el tipo de virus, la forma de contagio, la efectividad de la vacunación y el tiempo necesario para que esta mostrara su efecto profiláctico, así como otros aspectos que insistían en la rapidez de expansión de esta enfermedad por el mundo y en su benignidad ${ }^{39}$, siempre tratando de destacar el nivel científico de España para afrontar la epidemia, al disponer de suficiente reserva vacunal para combatirla ${ }^{40}$. Con frecuencia se recurrió a escritos realizados por científicos, al ser mejores conocedores de la enfermedad $y$, de este modo, dar mayor verosimilitud a las recomendaciones e información que se proporcionaba. Este tipo de noticias, avaladas por expertos o profesionales sanitarios, parecían dar respuesta al alto grado de alarma social que la citada pandemia provocó entre la población ${ }^{41}$. De hecho, en uno de estos reportajes, se manifestaba que "el miedo a la gripe asiática es más peligroso que la enfermedad misma", destacando que un comunicado de la OMS declaraba la gripe asiática "como de las más benignas", dada su baja mortalidad en población general"42.

El 5 de octubre se publicó en la prensa una nota de la Dirección General de Sanidad en la que se anunciaba la epidemia de gripe asiática en el país, que comenzaba a extenderse a partir "de las vías fronterizas y de los puertos de mayor tráfico". Aun así, se insistía en un número "no muy elevado" de afectados y en su benignidad, describiendo una situación sanitaria "francamente buena" y resaltando que "los españoles pueden tener la seguridad de que frente a la epidemia gripal dispondrán de los recursos que la ciencia aconseja" ${ }^{\prime 3}$.

En 1960 apareció la noticia sobre una nueva vacuna de gripe estacional desarrollada por científicos británicos del Centro de Investigación sobre la Gripe de Londres. En la misma página otra noticia informaba de la gravedad y extensión de la gripe estacional en Francia, Austria y Alemania, sin hacer alusión alguna, tampoco en esta ocasión, a la situación en España ${ }^{44}$. En febrero de ese año la prensa ya hace alusión directa a "La Pandemia gripal en España". En un artículo de carácter divulgador y científico, el autor refiere que la gripe "aqueja a casi todas las poblaciones de Europa" y respecto a la vacunación se informaba que "Los virólogos se admiran de la prodigiosa facultad de mutación del virus de la gripe y de su transformación para poder burlar el ataque de los anticuerpos", reflejando así una cierta ambivalencia, al cuestionar la eficacia de la vacuna, aspecto este siempre controvertido debido a la mutabilidad estacional de los virus $^{45}$. En años posteriores, encontramos noticias que recogen esta misma temática ${ }^{46}$.

En 1967, en el marco del organismo sanitario internacional, se formulan los requerimientos para la elaboración de la vacuna inactivada contra la gripe, que fueron publicados como anexo al 20 informe técnico del Comité de Expertos en Estandarización Biológica de la $\mathrm{OMS}^{47}$. Y en diciembre de ese año detectamos una pequeña noticia sobre "Una posible epidemia de gripe asiática en Nueva York"48, que durante 1968 y en los años posteriores dió lugar a numerosas noticias de prensa.

En enero de 1968, las autoridades sanitarias españolas, ante las noticias sobre "los casos de gripe actuales... en otros países europeos y especialmente en Inglaterra" vuelven a lanzar una nota de prensa, advirtiendo que "No existe motivo de alarma", anunciando así que ya se habían tomado las medidas necesarias para que el Centro Nacional de Virología produjera la vacuna antigripal necesaria por "si llegara el momento de que fuera aconsejable una vacunación de amplios sectores de la población"49. 
En 1978, la prensa publicó la recomendación de la OMS en torno al uso, por primera vez, de una vacuna trivalente para la siguiente temporada, que contendría diferentes cepas del virus ${ }^{50}$. Encontramos entonces noticias divulgativas a favor del uso de la vacuna como medio preventivo de la enfermedad, basadas en que eran vacunas gripales polivalentes. Se informaba que el sistema de vigilancia epidemiológica mundial de la OMS detectaba los cambios y mutaciones de los virus, lo que contribuía a hacer una vacuna acorde con las cepas circulantes, generalmente efectiva, aunque se reconocía que, en ocasiones, el virus podía sufrir una modificación no prevista ${ }^{51}$. Igualmente se hacía referencia a que el uso de la vacunación solo debía aplicarse a pacientes de riesgo: adultos y niños con enfermedades crónicas, mayores de 75 años y personal médico y sanitario, evitando la vacunación masiva de niños y adultos sanos, destacándose, en todas ellas, que las recomendaciones sobre la vacunación antigripal estaban avaladas por la $\mathrm{OMS}^{52}$.

Este tipo de noticias solían publicarse en los meses de otoño-invierno, época de aparición de la enfermedad, y en ellas se aprecia un cierto carácter científico, describiendo las medidas preventivas, los síntomas y el tratamiento para su alivio ${ }^{53}$, con el aparente objetivo de promover la educación sanitaria de la población sobre este tipo de enfermedades comunes. Del mismo modo, se reflejaba la distribución de vacunas antigripales y su disponibilidad en farmacias, así como los avances en su investigación ${ }^{54}$.

Finalmente, cabe destacar que el uso de la vacuna en España, como en muchos otros países del mundo, solo ha sido aplicada a determinados grupos de riesgo, por lo que se ha mantenido su morbilidad, si bien se ha conseguido disminuir ostensiblemente la mortalidad causada por ella (Navarro García, 2002).

\section{CAMPAÑAS DE VACUNACIÓN CONTRA LA POLIOMIELITIS}

En España, la poliomielitis se había presentado de manera esporádica, surgiendo como epidémica, como en otros países de Europa y del mundo, a finales del siglo XIX. Posteriormente, se registraron diversos brotes de la enfermedad en 1916, 1930, 1932 y 1942. El cambio en el patrón endemoepidémico que empezó a mostrar la enfermedad en todo el mundo a lo largo de este siglo planteó la exigencia de dar una respuesta eficaz por parte de la comunidad científica inter- nacional, de manera que, en 1948, la I Asamblea General de la OMS incorporó la poliomielitis en su agenda ${ }^{55}$ y poco después, en 1949 , se creó la Oficina Regional Europea de la OMS, que asumió e inició el Programa de Polio de dicha Oficina Regional en 1953. Hasta el desarrollo de la primera vacuna segura en 1955, por parte de Jonas Salk, el tratamiento de la enfermedad se basó en los cuidados del paciente (Théodorides, 1991), pero, progresivamente, fueron poniéndose en marcha las primeras campañas de vacunación masiva.

La prensa española fue prolífica en noticias sobre la poliomielitis desde los comienzos de la década de los cincuenta. Especialmente extenso en noticias fue el año 1955, cuando se publicaron los resultados del gran ensayo de la vacuna Salk en los EE. UU., al ser considerado el primer medio eficaz para prevenir la enfermedad, dando lugar a diversos titulares triunfalistas como "Absoluta eficacia de la vacuna contra la poliomielitis", "otro bastión que cede. La poliomielitis" o "La parálisis infantil ha sido vencida"

También se difundió ampliamente la preocupación por el incidente Cutter en Estados Unidos ${ }^{57}$. Este hecho sirvió de justificación a las autoridades sanitarias españolas para no implantar en ese momento un programa de vacunación antipolio, basándose en la falta de seguridad de la vacuna ${ }^{58}$. Poco después se recogería el esfuerzo realizado para investigar el problema y mejorar la seguridad de la "nueva" vacuna Salk ${ }^{59}$ y el anuncio de haberse reiniciado las inmunizaciones en los EE. UU., a pesar de algunas resistencias por parte de la población ante el grave incidente ("El cincuenta por ciento del país se resiste a ser inoculado con la vacuna Salk")60. No obstante, también llegaron noticias de los buenos resultados de la vacuna Salk en el control de la enfermedad ${ }^{61}$. Asimismo, se publicaron noticias sobre las vacunas vivas que, se afirmaba, iban a poder utilizarse con seguridad ${ }^{62}, y$ acerca de las recomendaciones de la OMS promoviendo la vacunación en masa contra la polio, por considerarla segura ${ }^{63}$.

Asimismo, la prensa recogió la celebración en Madrid del V Simposium de la Asociación Europea contra la Poliomielitis, destacando que el representante español en ese foro había anunciado el inicio de la vacunación contra la polio en España con vacuna tipo Salk ${ }^{64}$. Poco después, se publicaron las declaraciones del delegado de sanidad de Madrid, reconociendo que la escasez de recursos hacía imposible el abordaje de una campaña masiva debido al alto coste y 
la escasez de recursos económicos para afrontarla ${ }^{65}$. La cuestión del alto coste económico que suponía la vacunación antipolio comenzó a divulgarse a partir de la celebración del VI Simposium de la AEP en Munich en $1959^{66}$

La vacuna Salk comenzó a utilizarse en nuestro país en 1957, aunque de modo muy restringido, pero la primera campaña de inmunización masiva fue la realizada en 1963 y 1964, con vacuna oral Sabin (Rodríguez Sánchez y Seco Calvo, 2009). En esta primera campaña una de las estrategias de difusión utilizadas fue la de comunicar a los medios, entre ellos la prensa escrita, las noticias que surgían en torno a dicha campaña, en su comienzo y durante el desarrollo de sus fases, de modo que, tras su realización, los diarios nacionales se hicieron eco de tales acontecimientos ${ }^{67}$, destacando los éxitos en el desarrollo de la campaña piloto e instando a los padres para que se responsabilizaran y participaran en ella "por el bien de sus hijos"68. También mencionaron lo relativo a la campaña del año siguiente, resaltando los buenos resultados obtenidos el año anterior ${ }^{69}$, especificando que la primera fase se llevaría a cabo en la primavera de $1965^{70}$.

Tras esta primera campaña, que abarcó a los menores de 7 años, la incidencia de la enfermedad descendió drásticamente, aunque el número de casos volvió a elevarse a partir de 1965. La vacunación contra la polio en España fue voluntaria y gratuita, aunque no siempre se siguieron estrictamente las recomendaciones de la OMS y de la Asociación Europea contra la Poliomielitis en su aplicación.

Y aunque, efectivamente, los resultados de las campañas fueron buenos, y la morbilidad, a partir de esa primera campaña, disminuyó de manera importante, la información disponible en la prensa se hizo progresivamente más escasa, centrándose sobre todo en los brotes que ocasionalmente se registraban en zonas periféricas, más o menos marginales, de las grandes ciudades, como los registrados en Vallecas y Orcasitas en $1967^{71}$.

En 1975 las campañas de inmunización fueron sustituidas por un calendario de vacunación infantil que conllevó el control efectivo de la enfermedad en los primeros ochenta, registrándose el último caso de poliomielitis autóctona en 1989 (Porras Gallo, y Báguena, 2013; Caballero Martínez y Porras Gallo, 2016).

\section{CAMPAÑAS DE VACUNACIÓN CONTRA LAS ENFERMEDADES INFECCIOSAS INFANTILES (SARAMPIÓN, PAROTIDITIS, RUBEOLA)}

El sarampión es una enfermedad de presentación epidémica, muy contagiosa y que se transmite por vía aérea y/o por contacto con las secreciones de los pacientes afectados (Domínguez García y Borrás López, 2008), siendo la vacunación sistemática la principal y fundamental estrategia de salud pública en la lucha contra la enfermedad ${ }^{72}$.

La rubéola es una infección vírica, por lo general leve, que afecta principalmente a niños y adultos jóvenes. Su importancia deviene del hecho de que la infección por rubéola en las mujeres embarazadas puede causar la muerte del feto o defectos congénitos en la forma de síndrome de rubéola congénita $(\mathrm{SRC})^{73}$. En 1977, la vacuna contra la rubéola fue introducida en nuestro país para ser administrada a las niñas a los 11 años de edad (Nájera, et al, 1973), siguiendo las primeras recomendaciones de la $\mathrm{OMS}^{74}$. En 1981 se incluyó la vacuna combinada, triple vírica (sarampión, parotiditis y rubéola) en el calendario vacunal para ser administrada a los 15 meses de edad, aunque se continuó vacunando contra la rubéola durante unos años más a la cohorte de niñas de 11 años (Pachón del Amo, 2004).

La parotiditis es una enfermedad viral humana que afecta principalmente a niños adolescentes y adultos jóvenes. La primera vacuna contra la parotiditis se descubrió en 1963, siendo autorizada por primera vez en los EE. UU. en $1967^{75}$. En España la vacunación contra la parotiditis se introdujo en 1981 con la vacuna combinada triple vírica, en una sola dosis, administrada a los 15 meses de edad.

Hasta finales de los años 60, la prensa no recogió noticias relacionadas con la vacunación contra este tipo de enfermedades infecciosas, ya que no se habían instaurado aún los programas de vacunación para combatirlas. Tangencialmente, aparecen algunas noticias referidas a los estudios llevados a cabo por los servicios de virología para tratar de identificar y aislar los virus que provocaban estas enfermedades ${ }^{76}$.

En España la primera campaña piloto de vacunación contra el sarampión se realizó en 1968; fue llevada a cabo en once provincias españolas, y se vacunó a los niños de 9 a 24 meses con una vacuna antisarampión, que contenía la cepa Beckenham 31. La vacuna pro- 
vocó reacciones secundarias de moderada intensidad, por lo que en 1970 fue retirada (Gimeno de Sande, et al, 1972). Esta campaña se mencionó en prensa a principios de junio del 68. Se inició en Madrid y estuvo abierta a todo el vecindario de la ciudad interesado en vacunar a sus hijos para prevenir la enfermedad. La administración de la vacuna se realizaba en los centros de higiene infantil dependientes de la Jefatura provincial de sanidad o en dicha jefatura ${ }^{77}$. Se informó que el día 1 de octubre de ese mismo año daría comienzo una campaña de vacunación contra la difteria, tétanos, tosferina, poliomielitis y sarampión publicitada a través de la prensa de la capital ${ }^{78}$. Sin embargo, sorprende que no se den más de detalles de la campaña piloto nacional, realizada en 11 provincias, en la que se vacunó a 10.000 niños de 9-24 meses de edad. Tan solo encontramos una referencia a este hecho en una noticia publicada en enero de 1969, en la que se evidencia un error pues menciona que la campaña se llevó a cabo en 14 provincias $^{79}$.

En 1970 cabe destacar algunas noticias en las que profesionales médicos insistían sobre la importancia de la vacunación en enfermedades infecciosas, como el sarampión y la rubeola, si bien por entonces, estas vacunas no estaban aún disponibles en España ${ }^{80}$.

En 1971 llegan las primeras noticias sobre las pruebas norteamericanas de una vacuna combinada, contra el sarampión y la parotiditis ${ }^{81}$, y España se plantea, ya en 1972, reintroducir la vacuna contra el sarampión (Báguena, MJ, Mariño, L., 2017).

En 1973 ya se habían puesto en marcha las campañas de vacunación infantil contra la difteria, tétanos, tosferina y poliomielitis ${ }^{82}$, antes de que la 27ạ Asamblea Mundial de la Salud de la OMS, celebrada en mayo de 1974, decidiera implantar a nivel global el Programa Ampliado de Inmunización (PAI), recomendando a los gobiernos el uso de vacunas para luchar contra seis enfermedades muy prevalentes en la infancia: tuberculosis (BCG), difteria, tétanos, tos ferina (DTP), poliomielitis y sarampión. Siguiendo estos criterios de la OMS, España decidió implantar lo que sería su primer calendario de vacunación infantil en 1975 , que inicialmente no incluía la vacuna del sarampión, aunque la Dirección General de Sanidad comenzó a mediados de ese año a ofrecer las vacunas del sarampión y la rubéola, tanto a los padres como a los centros educativos, para inmunizar a los niños en edad escolar con una nota de prensa que refería "Los directores y médicos de grupos escolares, guarderías y otros centros que alberguen grupos de niños pueden solicitar la presencia de los equipos de vacunación que precisen" ${ }^{13}$. En ocasiones la prensa divulgaba consejos en artículos firmados por médicos colaboradores, que apelaban a que "Los padres deben conocer perfectamente el calendario de vacunaciones" preguntándose "¿Por qué nuestros niños no se vacunan de sarampión? solamente por desconocimiento"84, por lo que de alguna manera se culpabilizaba a los padres del problema, aunque en otras ocasiones se admitía que no siempre la disponibilidad de las vacunas era adecuada $^{85}$. En 1977 se modificó el calendario vacunal, incluyendo la vacuna del sarampión, para ser administrada a los 9 meses de edad.

Este año también aparecieron en varias ocasiones noticias relativas a la Organización Mundial de la Salud y a la importancia que esta institución internacional otorgaba a las campañas de vacunación infantil para prevenir o erradicar enfermedades infecciosas asociadas a la infancia, que aún causaban una mortalidad elevada, sobre todo, en las zonas del mundo más empobrecidas. En torno al Día Mundial de la Salud, promovido por la OMS y celebrado el 7 de abril, el diario $A B C$ recogió su lema para ese año "Proteja a sus hijos vacunándolos". La pauta propuesta por la OMS para la inmunización primaria de los niños pequeños era la de administrar la vacuna del sarampión a los 12 meses de edad, seguida de la de la parotiditis, y la de la rubeola ${ }^{86}$.

La OMS recomendó a los Estados miembros la implantación de campañas de vacunación a largo plazo y se brindaba a prestar soporte técnico en la planificación y en la formación de personal ${ }^{87}$. En este marco de interés internacional en el tema de la prevención de enfermedades transmisibles de la infancia, la prensa recogió también la iniciativa de la Comunidad Europea para colaborar en las campañas de vacunación infantil a nivel mundial en países pobres ${ }^{88}$.

Como ocurre con otras enfermedades de las estudiadas, al terminar la dictadura franquista, se incrementaron las noticias en las que se resaltaba la ventaja de las vacunas de virus vivos atenuados, promoviendo la vacunación contra estas enfermedades. En su mayoría, estas noticias estaban firmadas por colaboradores médicos habituales de las secciones específicas dedicadas a la Medicina $y$, a veces, por figuras médicas de reconocido prestigio ${ }^{89}$. También se reflejó la organización de campañas vacunales en algunas épocas del año. En una de las noticias recogidas, se publicita la campaña de vacunación de primavera que tendría lugar en Madrid contra la po- 
liomielitis, difteria, tétanos, tosferina, sarampión y rubeola, organizada por la Dirección General de Salud Pública. Las vacunaciones se llevarían a cabo en la dirección de salud y centros dependientes, jefaturas locales de sanidad de los municipios de la provincia, centros de la Seguridad Social y Ayuntamiento, informándose de que se trataba de un servicio gratuito para todos los niños ${ }^{90}$.

En otras se destacaba que los niños vacunados no podían transmitir la infección a los contactos y que podían combinarse con otras vacunas del mismo tipo, como la de la rubeola y la parotiditis, aunque no se llevó a la práctica hasta la modificación del calendario vacunal en $1981^{91}$. Asimismo, se insistía en la importancia de las vacunaciones infantiles contra estas enfermedades víricas ${ }^{92}$, destacando una noticia publicada en 1984 sobre la vacuna triple vírica que, aun teniendo una alta eficacia comprobada, no se usaba en campañas de vacunación masivas, probablemente por su "alto coste económico"93.

Así pues, el año 1981 fue clave en el proceso de prevención de las tres enfermedades estudiadas. Por un lado, se había modificado el listado de enfermedades de declaración obligatoria, incorporando enfermedades como el tétanos, la tosferina, la parotiditis y la rubeola ${ }^{94}$, dada su importancia epidemiológica, pues el anterior se había realizado en 1944. Por otro lado, en abril, se anunció un nuevo calendario vacunal, en el que se incluyó como novedad la vacuna contra la parotiditis y la rubeola a los 15 meses, junto a la del sarampión ${ }^{95}$. Posteriormente, una segunda dosis con vacuna triple vírica comenzó a administrarse a todos los niños y niñas de 11 años, pero su incorporación fue desigual entre Comunidades Autónomas, como consecuencia de la diversidad en el traspaso de competencias en Salud Pública entre los años 1979 y 1985, siendo Cataluña la primera en introducirla en 1988.

\section{CONCLUSIÓN}

Podemos decir que la prensa en el periodo de estudio no trató el tema de la vacunación de una manera homogénea.

En los años 50, la mayor parte de las noticias relacionadas con las campañas de vacunación contra la viruela fueron triviales, referidas a lugares y horarios de vacunación. La rabia sólo fue noticia cuando se producía algún brote epidémico. La poliomielitis tuvo mucha cobertura en prensa desde 1955, tras el descubrimiento de la vacuna Salk y la posterior preocupación por el incidente "Cutter", asi como durante la primera campaña de vacunación española. En el caso de la gripe, las noticias fueron numerosas por las pandemias sufridas en esos años y la alarma social que provocaron. No obstante, en los años 50 y 60, las noticias estuvieron parcialmente sesgadas, debido al uso propagandístico que se hizo de la prensa. Las autoridades sanitarias, mediante notas de prensa o declaraciones públicas, intentaron mostrar un país con una buena situación sanitaria, dotada de suficientes recursos y adaptada a las recomendaciones internacionales, minimizando el problema real que suponían estas enfermedades, cuyos brotes, como el de gripe asiática de 1957 o el de viruela de 1961, fueron silenciados o atribuidos a casos importados.

En los años 70 y en el período democrático, se aprecia un cambio de enfoque: se multiplicaron las noticias sobre las recomendaciones de los organismos internacionales, como la OMS, acerca de la vacunación como medio para prevenir otras enfermedades infecciosas, como el sarampión, la rubeola o la parotiditis, aparecen más noticias firmadas por profesionales sanitarios, ofreciendo información veraz sobre su importancia y gravedad, contribuyendo, así, a la divulgación educativa en torno a su control y prevención mediante la inmunización, como medida más eficaz contra dichas enfermedades. 


\section{NOTAS}

1 Este trabajo se ha realizado en el marco del proyecto de investigación del MINECO-Fondos FEDER (Ref. HAR2015-70688-C2-2P).

2 1951: mayo a septiembre; 1955: abril a junio; 1956: febrero; 1957: marzo, abril, septiembre a diciembre; 1958: enero a marzo, septiembre y octubre; 1961: febrero a mayo; 1963: octubre a diciembre; 1965: febrero; 1967: mayo; 1968: mayo y junio; 1969: enero; 1981: Años 1981, 1984 a 1986 completos.

3 Regulado en la Real Orden de 24 de julio de 1871, Gazeta de Madrid.

4 Ley de 25 de noviembre de 1944 de Bases de Sanidad Nacional Base Cuarta. Lucha contra las enfermedades infecciosas, Gazeta de Madrid.

5 Diario La Vanguardia, 15-02-1955, p. 4; Diario La Vanguardia, 19-02-1955, p. 3.; Diario La Vanguardia, 26-02-1955, p. 3.

6 Diario La Vanguardia, 24-02-1955, p. 4.

7 Diario La Vanguardia, 6-04-1955, p. 18.

8 ORGANIZACIÓN MUNDIAL DE LA SALUD. Serie de informes técnicos. Na 180. Normas para las sustancias biológicas. 5 . Normas para la Vacuna Antivariólica. Informe de un Grupo de Estudio, 1959

9 Diario La Vanguardia, 21-02-1961, p. 6; Diario ABC, 22-21961, p. 51; Diario YA, 3-3-1961, portada; Diario La Vanguardia, 7-03-1961, p. 9.

10 Diario La Vanguardia, 12-03-1961, p. 27.

11 Diario La Vanguardia, 21-03-1961, p. 6; Diario YA, 21-31961, portada; Diario ABC, 21-3-1961, p. 51

12 Diario La Vanguardia, 17-01-1962, p. 6.

13 ORGANIZACIÓN MUNDIAL DE LA SALUD. Serie de Informes Técnicos. № 283. Comité de Expertos de la OMS en Viruela. Primer Informe. OMS, Ginebra, 1964.

14 Diario ABC, 07-04-1965, p. 61-62.

15 Diario La Vanguardia, 5-04-1975, p. 5; Diario ABC, (Edición Andalucía), 08-04-1975, p. 108.

16 Diario La Vanguardia, 17-12-1972, p. 53.

17 Diario La Vanguardia, 20-02-1972, p. 51 (Una Victoria Inminente. Hacia la desaparición de la Viruela); Diario La Vanguardia, 23-04-1972, p. 53 (La vacuna despreciada).

18 Diario $A B C, 29-11-1975$, p. 52.

19 Diario $A B C, 22-08-1976$, p. 28

20 Diario ABC, 08-07-1979, p. 50.; Diario La Vanguardia, 2111-1979, p. 44.

21 OMS. 33a Asamblea Mundial de la Salud. Ginebra, 5-23 de mayo, 1980 (WHA 33/1980/REC/1_spa.pdf), p. 2.

22 Decreto de 4 de febrero de 1955, por el que se aprobó el Reglamento de Epizootias.

23 WHO EXPERT COMMITTEE ON RABIES, Second Report, WHO, Technical Report Series, 1954, no 82.
24 WHO EXPERT COMMITTEE ON RABIES, Third Report, WHO, Technical Report Series, 1957, no 121.

25 Diario YA, 2-6-1951; Diario ABC, 7-04-1953, p. 25; Diario $A B C, 3-06-1954$, p. 37; Diario YA, 2-4-1955, p. 9; Diario $A B C$ (Sevilla), 16-05-1956, p. 37; Diario YA, 3-3-1957; ABC (Sevilla), 6-02-1958, p. 30; DiarioABC, 22-07-1960, p. 67; Diario YA, 25-1-1981.

26 Diario $A B C$ (Sevilla), 17-09-1975, p. 30 y 84; Diario ABC, 20-06-1976, p. 41; Diario ABC, 24-07-1976, p. 39

27 Diario ABC (Sevilla), 11-08-1965, p. 24; Diario ABC, 15-061967 , p. 71.

28 Diario $A B C, 10-07-1965$, p. 32

29 Diario ABC (Sevilla), 30-05-1972, p. 53; Diario ABC (SeviIla),19-09-1975, p. 7; Diario ABC (Sevilla) 07-11-1975, p. 79.

30 Diario ABC (Sevilla), 5-06-1965, p. 57-58.

31 Diario $A B C, 14-07-1967$; Diario $A B C, 09-05-1970$, p. 46; Diario ABC, 16-02-1973, p. 68; Diario ABC (Sevilla), 06-031973, p. 79; Diario ABC, 05-10-1975, p. 81.

32 Diario $A B C$, 20-02-1970, p. 53; Diario ABC, 27-05-1972, p. 61.

33 Diario ABC, 23-08-1973, p. 31

34 Diario ABC, 20-06-1976, p. 41; Diario YA, 11-4-1981, p. 36; Diario YA, 14-11-1985, p. 34

35 Orden de 14 de junio de 1976 por la que se dictan normas sobre medidas higiénico-sanitarias en perros y gatos de convivencia humana y Orden por la que se modifican determinados artículos de la de 14 de junio de 1976 sobre medidas higiénico-sanitarias en perros y gatos de convivencia humana.

36 Diario YA, 26-01-1985, p. 28.

37 Diario $A B C, 17-09-1975$, p. 84; Diario $A B C, 20-06-1976$, p. 41-42; Diario ABC (Sevilla), 14-08-1984, p. 22; Diario ABC (Sevilla), 18-06-1985, p. 54.

38 WHO EXPERT COMMITTEE ON INFLUENZA. First Report. WHO, Technical Report Series, 1953, No. 64.

39 Diario $A B C, 11-07-1957$, p. 30

40 Diario ABC, (Sevilla), 22-10-1957, p. 26; Diario ABC, 20-111957, p. 42

41 Diario YA, 25-9-1957, portada; Diario YA, 28-9-1957, portada; Diario YA, 11-10-1957, p. 2; Diario ABC, 15-10-1957, p. 32.

42 Diario $A B C$, 26-06-1957, p. 40; Diario ABC (Sevilla), 28-091957, p. 13; Diario YA, 25-09-1957, portada; Diario YA, 2809-1957, portada; Diario YA, 11-10-1957, p. 2; Diario ABC, 15-10-1957, p. 32.

43 Diario ABC, 05-10-1957, p. 33

44 Diario ABC, 29-01-1960, p. 46

45 Diario ABC, 04-02-1960, p. 19; Diario ABC (Sevilla), 05-021960 , p. 5. 
46 Diario $A B C$, 15-01-1976, p. 46; Diario ABC, 29-01-1981, p. 28; Diario YA, 26-10-1986, p. 37; Diario YA, 1-11-1986, p. 33.

47 WHO Expert Committee on Biological Standardization. Twentieth report. Geneva, World Health Organization, 1968, Annex 2 (WHO Technical Report Series, No. 384); ABC SEVILLA (Sevilla), 12-01-1968, p. 22.

48 ABC (Madrid), 21-12-1967, p. 63.

49 ABC SEVILLA (Sevilla), 12-01-1968, p. 22.

50 Diario ABC (Sevilla), 26-11-1978, p. 25.

51 Diario ABC (Sevilla), 09-01-1981, p. 28.

52 Diario $A B C$, 23-10-1977, p. 38; Diario ABC, 20-01-1979, p. 29; Diario $A B C, 20-09-1981$, p. 56; Diario $A B C, 16-11-1986$, p. 69; Diario YA, 5-09-1984, p. 28.

53 Diario $A B C, 19-10-1980$, p. 42

54 Diario YA, 2-04-1984, pp. 3-4; Diario YA, 24-09-1986, p. 35.

55 ORGANISATION MONDIALE DE LA SANTÉ. Interim Commission of the World Health Organization. (Fifth session). First World Health Assembly. 7 July 1948, 12. 1. 7. 5.1 Acute Anterior Poliomyelitis (infantile Paralysis). Off. Rec. WHO, 10 , page 14

56 Diario $A B C$, 31-03-1955, p. 31; Diario ABC (Sevilla), 31-031955 p. 14; Diario $A B C, 01-04-1955$, p. 30 y 32; Diario $A B C$, 07-04-1955, p. 36; Diario ABC (Sevilla), 12-04-1955 p. 21; Diario $A B C, 13-04-1955$, p. 10; Diario ABC (Sevilla), 13-041955 p. 15-17; Diario $A B C, 15-04-1955$, p. 39; Diario $A B C$ (Sevilla), 15-04-1955, p. 28; Diario ABC, 19-04-1955, p. 55; Diario ABC, 20-04-1955, p. 34; Diario ABC (Sevilla), 24-041955; Diario ABC, 24-04-1955, p. 49; Diario YA, 12-4-1955, portada; Diario YA, 13-4-1955, portada; Diario YA, 14-41955, portada.

57 Diario ABC (Sevilla), 30-04-1955, p. 33; Diario ABC, 01-051955 , p. 34; Diario $A B C, 04-05-1955$, p. 37; Diario $A B C$, 05-05-1955, p. 38; Diario $A B C, 07-05-1955$, p. 21; Diario $A B C$, 08-05-1955, p. 49; Diario $A B C, 11-05-1955$, p. 23; Diario $A B C, 12-05-1955$, p. 41; Diario ABC, 20-05-1955, p. 39; Diario YA, 25-5-1955, portada; Diario YA, 26-5-1955, portada; Diario YA, 3-5-1955, p. 3; Diario YA, 4-5-1955, p. 9; Diario YA, 8-5-1955, portada; Diario YA, 12-5-1955, p. 2; Diario YA, 17-5-1955, p. 3; Diario YA, 20-5-1955, portada.

58 Diario $A B C, 01-07-1955$, p. 32.

59 Diario $A B C, 20-05-1955$, p. 39; Diario ABC (Sevilla), 22-051955, p. 35; Diario ABC (Sevilla), 26-05-1955, p. 22; Diario $A B C, 26-05-1955$, p. 43; Diario $A B C, 28-05-1955$, p. 24; Diario $A B C, 03-06-1955$, p. 3; Diario $A B C, 08-06-1955$, p. 30; Diario YA, 1-5-1955, p. 8; Diario YA, 10-5-1955, p. 3.

60 Diario ABC, 24-08-1955, p. 18

61 Diario ABC, 03-09-1955, p. 33; Diario ABC, 06-09-1955, p. 19; Diario $A B C, 23-12-1955$, p. 47.

62 Diario $A B C, 08-01-1956$, p. 30; Diario ABC, 10-10-1956, p. 20; Diario $A B C$ (Sevilla), 02-01-1957, p. 18; Diario ABC, 2607-1957, p. 34; Diario ABC, 06-11-1957, p. 27; Diario ABC, 20-11-1957, p. 62.

63 Diario $A B C, 22-02-1956$, p. 38.
64 Diario ABC, 30-09-1958, p. ; Diario La Vanguardia, 30-091958, p. 14; Diario YA, 1-10-1958, p. 13.

65 Diario ABC, 1-11-1958, p. 44.

66 Diario ABC, 12-09-1959, p. 23; Diario La Vanguardia, 1209-1959, p. 11; Diario La Vanguardia, 20-09-1959, p. 11; Diario YA, 31-10-1959, p. 12.

67 Diario ABC, 19-11-1963, p. 67; Diario La Vanguardia, 1911-1963, p. 23; Diario ABC, 12-03-1964, p. 69; Diario YA, 15-11-1963, p. 12; Diario YA, 19-11-1963, p. 11.

68 Diario $A B C, 20-11-1963$, p. 70

69 Diario ABC, 18-02-1965, p. 53.

70 Diario ABC, 18-02-1965, p. 45; Diario YA, 18-2-1965, portada y p. 12.

71 Diario $A B C, 13-05-1967$, p. 90.

72 ORGANIZACIÓN MUNDIAL DE LA SALUD. Sarampión. Nota descriptiva. Marzo de 2016. Disponible en: http://www. who.int/mediacentre/factsheets/fs286/es/.

73 ORGANIZACIÓN MUNDIAL DE LA SALUD. Rubéola. Nota descriptiva, marzo de 2016. Disponible en: http://www. who.int/mediacentre/factsheets/fs367/es/.

74 WHO. Rubella vaccines. WHO position paper. Weekly Epidemiological Record, N. 20, 2000.

75 The History of the vaccines. An educational resource by the College of Physicians of Philadelphia. Disponible en: http://www.historyofvaccines.org/themes/historyofvaccines/images/hov_text.png.

76 Diario $A B C, 15-05-1956$, p. 69.

77 Diario ABC, 08-06-1968, p. 94; Diario YA, 9-6-1968, p. 10.

78 Diario ABC, 05-10-1968, p. 93.

79 Diario ABC, 03-01-1969, p. 50; Diario La Vanguardia, 4-011969, p. 9.

80 Diario $A B C, 02-08-1970$, p. 134; Diario ABC, 24-10-1970, p. 51.

81 Diario $A B C, 05-10-1971$, p. 59.

82 Diario $A B C, 09-10-1973$, p. 53.

83 Diario $A B C, 23-02-1975$, p. 28

84 Diario ABC, 01-04-1976, p. 50

85 Diario $A B C, 15-08-1976$, p. 33.

86 Diario $A B C, 07-04-1977$, p. 26

87 Diario ABC, 21-05-1977, p. 49; Diario La Vanguardia, 2905-1977, p. 53.

88 Diario $A B C, 14-08-1977$, p. 27

89 Diario ABC, 05-06-1977, p. 59; Revista Blanco y Negro (Madrid), 29-06-1977, p. 81; Revista Blanco y Negro (Madrid), 27-07-1977, p. 69; Revista Blanco y Negro (Madrid), 3-081977, p. 69; Diario $A B C, 20-11-1977$, p. 55; Diario $A B C$, 22-10-1978, p. 45; Diario ABC, 5-11-1978, p. 46; Diario $A B C, 20-01-1979$, p. 37; Diario ABC (Sevilla), 25-11-1979, p. 38; Diario $A B C, 23-12-1979$, p. 45; Diario $A B C, 03-10-$ 1982, p. 55; Diario $A B C, 26-02-1984$, p. 50; Diario $A B C$ 
(Sevilla), 08-07-1984, pp. 49-50; Diario ABC, 19-05-1985, p. 59.

90 Diario ABC, 14-04-1981, p. 36; Diario ABC (Sevilla), 06-051981, p. 42.

91 Diario ABC (Sevilla), 02-04-1981, p. 26; Diario ABC (Sevilla), 06-05-1981, p. 30.
92 Diario $A B C, 03-10-1982$, p. 55.

93 Diario $A B C, 26-02-1984$, p. 50.

94 Diario ABC (Sevilla), 01-03-1981, p. 28.

95 Diario $A B C, 02-04-1981$, p. 26.

\section{BIBLIOGRAFÍA}

Báguena Cervellera, Mạ José; Mariño Gutiérrez, Lourdes (2017), "La participación española en los programas de la OMS para el control de la rabia (1952-1975)". En: Zarzoso, Alfons; Arrizabalaga, Jon (eds.), Al servicio de la salud humana: La historia de la medicina ante los retos del siglo XXI, SEHM, pp. 117-122.

Ballester Añón, Rosa (2016), “España y la Organización Mundial de la Salud en el contexto de la Salud Pública Internacional (1948-1975)". Discurso de recepción de la académica electa. Valencia, Real Academia de Medicina de la Comunidad Valenciana.

Caballero Martínez, Ma Victoria, Porras Gallo, Mạ Isabel (2016), "El problema de la poliomielitis entre 1955 Y 1975. Los casos de España, Francia, Bélgica, Portugal y Reino Unido". En: Porras Gallo, Mạ Isabel; Báguena Cervellera, MãJosé; Ayarzagüena Sanz, Mariano; Martín Espinosa, Noelia Mạ (coords.), La Erradicación y el Control de las enfermedades infecciosas, Madrid, Libros La Catarata, pp. 208- 232.

Campos Marín, Ricardo (2004), “La vacunación antivariólica en España durante el siglo XIX". Asclepio, 55, pp. 3-6.

Duro Torrijos, José Luis (2014), Los inicios de la lucha contra la viruela en España. Técnica e ideología durante la transición de la inoculación a la vacuna. Alicante, Universidad de Alicante, Tesis doctoral.

Duro Torrijos, José Luis, Tuells Hernández, José (2015), “La gripe española según el diario “España Médica” (1918-1919)", Vacunas, 16(2), pp. 81-86.

Gimeno de Sande, Alfredo; Nájera Morrondo, Rafael; Nájera Morrondo, Enrique; Ortiz Berrocal, A; Pérez Gallardo, Florencio (1972), "Resultados de la campaña de vacunación antisarampionosa de 1968", Revista de Sanidad e Higiene Pública, 46, pp. 805-22.

Mariño Gutiérrez, Lourdes; Báguena Cervellera, Mạ José (2016), "La epidemia de viruela de 1961 del Hospital del Rey: ¿una amenaza para la salud pública y un descrédito para el régimen?" Comunicación presentada en el XI Congreso de la Asociación de Demografía Histórica, Cádiz 2016.

Marset Campos, Pedro; Sáez Gómez, José Miguel; Martínez Navarro, Fernando (1995), "La Salud Pública durante el franquismo", Dynamis, 15, pp. 211-250.

Martínez Martínez, Pedro Javier (2016), Noticias sobre vacunas en prensa española: cobertiura y análisis de contenidos (1955-2015), Alicante, Universidad de Alicante, Tesis Doctoral.
Molero Mesa, Jorge (1994), “Enfermedad y previsión social en España durante el primer franquismo (1936-1951). El frustrado seguro obligatorio contra la tuberculosis", Dynamis, 14 , pp. $199-225$.

Moulin, Anne Marie (1996), L'aventure de la vaccination. Paris, Fayard.

Nájera Morrondo, Enrique; Nájera Morrondo, Rafael; Pérez Gallardo, Florencio (1973), "The seroepidemiology of rubeIla. The independent analysis of current prevalence and past incidence in a serological Survey in Spain", Bulletin of the World Health Organization, 49, pp. 25-30.

Navarro Garcia, Ramón (2002), Análisis de la Sanidad en España a lo largo del Siglo XX, Madrid, Instituto de Salud Carlos III, Ministerio de Sanidad y Consumo.

Pachón del Amo, Isabel (2004), "Historia del programa de vacunación en España". En: Amela, Carmen (coord.), Epidemiología de las Enfermedades Incluidas en un Programa de Vacunación, Madrid, Emisa.

Payne, A.M.M (1953), "The influenza programme of WHO", Bulletin of the World Health Organization, 8 (5-6), pp. 755-774.

Perdiguero-Gil, Enrique (editor) (2015), Política, salud y enfermedad en España: entre el desarrollismo y la Transición democrática. Elche: Universidad Miguel Hernández, edición electrónica.

Porras Gallo, Maㅡ Isabel (2008), "Sueros y vacunas en la lucha contra la pandemia de gripe de 1918-1919 en España", Asclepio, 60 (2), pp. 261-288.

Porras Gallo, Ma Isabel y Báguena Cervellera, Ma José (2013), "La lucha contra la enfermedad mediante las campañas de vacunación en Madrid, Valencia y Castilla-La Mancha (19581975)". En: Porras Gallo, Ma Isabel; Ayarzagüena Sanz, Mariano; Heras Salord, Jaime de las; Báguena Cervellera, Ma José (coords.), El drama de la polio. Un problema social y familiar en la España franquista. Madrid, Los Libros de la Catarata, pp. 141-169.

Rodríguez-Ocaña, Esteban; Martínez Navarro, Ferrán (2008), Salud pública en España: de la Edad Media al siglo XXI. Granada. Escuela Andaluza de Salud Pública (Nueva Salud Pública).

Rodríguez Sánchez, Juan Antonio; Seco Calvo, Jesús (2009), "Las campañas de vacunación contra la poliomielitis en España en 1963”, Asclepio, 61(1), pp. 81-116. 
Santamaría, Encarnación (1990), "Las salas de vacunación en los hospitales peninsulares a principios de siglo XIX", Dynamis, 10, pp. 303-312.
Théodorides, Jean (1991), Des miasmes aux virus. Histoire des maladies infectieuses, Paris, Editions Louis Pariente. 